\title{
Creep damage analysis of simulated-HAZ notched bar specimens of modified 9Cr-1Mo steel
}

\author{
Takashi HONDA*, Takuya FUKAHORI*, Toshihide IGARI*, Yasuharu CHUMAN*, \\ Takumi TOKIYOSHI* and Alan CF COCKS** \\ * Research and Innovation Center, Mitsubishi Heavy Industries, LTD. \\ 5-717-1 Fukahori-machi, Nagasaki, Japan \\ E-mail: takashi3_honda@mhi.co.jp \\ ** Department of Engineering Science, University of Oxford, Parks Road, Oxford, UK
}

Received: 20 December 2016; Revised: 25 July 2017; Accepted: 22 August 2017

\begin{abstract}
From the standpoint of evaluating Type IV creep damage in the fine-grained heat affected zones (FGHAZ) of welded joints, an analysis method combining continuum damage mechanics (CDM) and a cavity nucleation model is proposed and applied to the creep testing of simulated-FGHAZ notched bars of mod. 9Cr-1Mo steel at $650^{\circ} \mathrm{C}$. The Perrin-Hayhurst $\mathrm{CDM}$ model is adopted, which considers both softening by precipitate coarsening and damage by creep cavities. For the cavity nucleation model, a proposal by Gonzalez and Cocks is employed, which considers the randomness of grain-boundary-facet orientations in a polycrystalline material and gives a nucleation rate that is a function of the creep strain rate and a tri-axiality factor. The critical value of the damage parameter, corresponding to the initiation of micro cracks due to the coalescence of creep cavities, is expressed in terms of a critical value of the number density of creep cavities as determined from grain-boundary-resistance model simulations by the present authors. Creep rupture experiments have been conducted for circumferentially notched bar specimens with two kinds of notch acuities. The applicability of the combined CDM and cavity nucleation model is demonstrated by comparing the distribution of creep cavities observed experimentally with the simulation results. The final rupture life of the circumferentially notched bar specimens was also predicted to within a factor of two.
\end{abstract}

Keywords : Creep, Creep damage, Creep cavity, Creep void, Type IV, Modified 9Cr-1Mo steel, Welded joints, Damage mechanics

\section{Introduction}

Residual life prediction of welded joints of modified 9Cr-1Mo steel has focused on power piping in USC boiler plants (Masuyama, 2000, Abe et al., 2004). Type IV creep damage in the FGHAZ (fine-grained heat affected zone) consists of creep cavities found in the subsurface of the piping. The mechanism of damage development is considered as follows from the perspective of continuum mechanics (Kawashima et al., 2004, Igari et al., 2011). The creep strain rate of the FGHAZ is faster than that of either the neighboring weld metal or base metal, and this can cause a tri-axial constraint in the FGHAZ depending on the difference in the creep strain rate. The maximum principal stress in the subsurface of the FGHAZ becomes higher than that at the surface, and this variation in maximum principal stress can explain the through-wall profile of small defect density in internal pressure burst tests of seam-welded elbows of 2.25Cr-1 Mo steel (Yamauchi et al., 2002). Accordingly, greater damage is found in the subsurface than on the surfaces of the piping. From the microscopic viewpoint, Type IV damage consists of the nucleation and coalescence of creep cavities having a size of the order of the grain size. According to the microscopic observation of cavity initiation in P91 FGHAZ by Masuyama et al. (2013), small sub-micron cavities initiate at triple points or precipitates at the boundaries of FGHAZ grains; these cavities grow and link to completely surround a grain and thus create cavities with the size of the FGHAZ grains, which subsequently coalesce with neighboring grain-size cavities, leading to the formation of microcracks. The number density of grain-size cavities (cavity density, for brevity) is usually used as a measure of creep damage in P91 welded joints (Fukahori et al., 2013, Komai, et al., 2016). Nondestructive inspection of the 
surface and subsurface of pipe welds is carried out to examine the current damage, such as the cavity density, and the results are employed to guide simulation-based predictions. Several approaches can be taken in terms of damage simulation for Type IV failure, such as: continuum mechanics together with the stress-based time fraction or the ductility fraction of the material; creep fracture mechanics using the $C^{*}$ parameter (Yatomi et al., 2003, Segle et al., 2000); creep cavitation mechanics assuming diffusion (Rice, 1981); use of a grain boundary-resistance model (Fukahori, et al., 2013, 2017); and/or damage mechanics (Hyde et al., 2003, Yao et al., 2007). It remains difficult, however, to determine an optimal method for expressing both the microscopic and macroscopic phenomena of actual Type IV damage. While the grain-boundary-fracture-resistance model, which describes the initiation, growth and coalescence of creep cavities leading to macro-crack formation (Kawashima et al. 2003, Igari et al., 2011), provides mechanism-based simulation results for cavity density, this cannot be easily extended to general structures which experience multiaxial stress states. A damage mechanics approach is appropriate for general structures, but the relation between the damage parameter and cavity density is not clear.

In this paper, we consider an analysis method for Type IV damage of modified 9Cr-1Mo steel by combining continuum damage mechanics (CDM) and cavity nucleation models. The Perrin-Hayhurst model (1999) is adopted as the CDM model, which considers both softening by precipitate coarsening and damage due to creep cavities. For the cavity nucleation model, the proposal by Gonzalez and Cocks (2014) is adopted, which considers the randomness of grain-boundary-facet orientations in a polycrystalline material and provides a damage growth criterion in terms of the creep strain rate and tri-axiality factor. A critical value of the damage parameter, corresponding to the initiation of micro cracks by the coalescence of creep cavities, is determined from the grain-boundary-resistance modeling simulation results (Fukahori et al., 2013, 2017). Before applying this method to a welded joint with tri-axial constraint and a hardness distribution in the FGHAZ, it is better to confirm its applicability to the simple condition of a simulated FGHAZ notched bar specimen with a uniform hardness and a tri-axial constraint due to the notch. In this context, creep rupture experiments were conducted on circumferentially notched bar specimens with two kinds of notch acuities. Comparing the distribution of creep cavity density in the experimental and simulated cases, the applicability of the method combining the CDM model and the cavity nucleation model was demonstrated.

\section{Creep tests of FGHAZ smooth and notched specimens}

\subsection{Tested material}

The tested material consists of a modified 9Cr-1Mo steel (SA-387 Gr.91) with the chemical composition shown in Table 1. Before simulating the multi-pass welding process, the test material was normalized $\left(1,050^{\circ} \mathrm{C} \times 30 \mathrm{~min} / 25 \mathrm{~mm}\right.$ thickness) and tempered $\left(780^{\circ} \mathrm{C} \times 30 \mathrm{~min} / 25 \mathrm{~mm}\right.$ thickness $)$. Although the heat affected zones of welded joints are generally made up of CGHAZ (coarse-grained heat affected zone), FGHAZ and inter-critical HAZ depending on the thermal history during the welding process, a simplified three-material model incorporating weld metal, FGHAZ and base metal is often adopted in the creep analysis of welded joints (Fukahori et al., 2013). This is based on the following assumptions: the creep deformation properties of the CGHAZ with small width (in the case of P91) are equivalent to those of weld metal; and the properties of the inter-critical HAZ are equivalent to those of base metal. When considering the FGHAZ in welded joints, there is a hardness distribution of about $190 \mathrm{Hv}$ (base metal side) $\sim 270 \mathrm{Hv}$ (weld metal side) across a width of $2 \sim 3 \mathrm{~mm}$. In this paper, in order to reproduce the tempered-martensite microstructure of the FGHAZ and a hardness of around $190 \mathrm{Hv}$, the tested material was subjected to a thermal history simulating the multi-pass welding process as shown in Fig. 1 . Specimens were held at $1,000^{\circ} \mathrm{C}$ for 5 seconds; then at $840^{\circ} \mathrm{C}$ for 5 seconds; and at $750^{\circ} \mathrm{C}$ for 2.5 hours in an electric furnace. Heating rates are $45 \sim 75^{\circ} \mathrm{C} / \mathrm{s}$ as shown in Fig1, and cooling is under air-cooled conditions. The microstructure thus obtained is shown in Fig. 2; the average grain size is $4 \sim 5 \mu \mathrm{m}$ and the hardness is $193 \mathrm{Hv}$ at a load of $98 \mathrm{~N}$.

Table 1 Chemical composition (wt \%)

\begin{tabular}{|c|c|c|c|c|c|c|c|c|c|c|c|c|}
\hline Steel & $\mathrm{C}$ & $\mathrm{Si}$ & $\mathrm{Mn}$ & $\mathrm{P}$ & $\mathrm{S}$ & $\mathrm{Cr}$ & $\mathrm{Mo}$ & $\mathrm{Ni}$ & $\mathrm{V}$ & $\mathrm{Nb}$ & Sol.Al & $\mathrm{N}$ \\
\hline $\begin{array}{c}\text { Mod.9Cr-1Mo } \\
\text { (SA-387 Gr. 91) }\end{array}$ & 0.09 & 0.36 & 0.46 & 0.009 & 0.001 & 8.49 & 0.98 & 0.26 & 0.20 & 0.08 & 0.01 & 0.050 \\
\hline
\end{tabular}




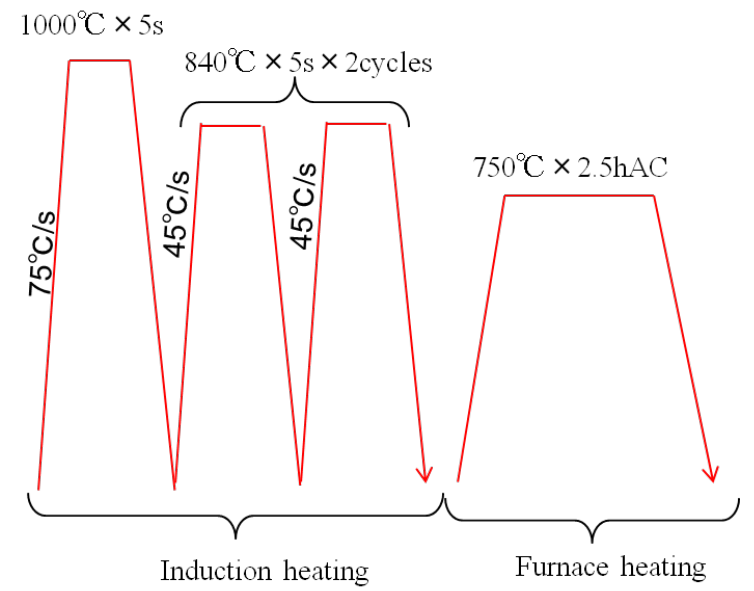

Fig.1 Schematic illustration of heat treatment

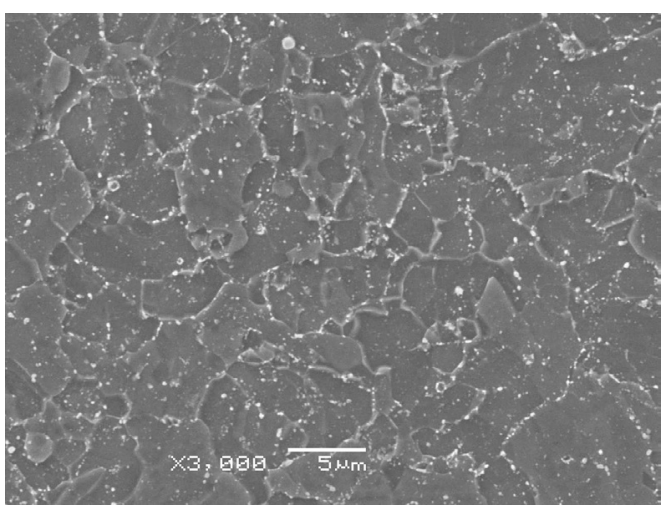

Fig.2 Microstructure of simulated FGHAZ material

\subsection{Test conditions and results}

Creep tests were carried out at $650^{\circ} \mathrm{C}$ under the test conditions described in Table 2. There are two types of specimens; a standard smooth round bar specimen, and a double notched round bar specimen with two kinds of notch acuities; the former is for obtaining the creep deformation properties of the FGHAZ and the latter is for obtaining a distribution of the cavity density and rupture life. Figure 3 depicts the configuration of notched round bar specimens R1 (sharp; notch radius of $1 \mathrm{~mm}$ ) and R3 (blunt; notch radius of $3 \mathrm{~mm}$ ). The rupture lives for the smooth and notched bar specimens are described in Fig.4 together with the averaged rupture curve of the welded joints (Yaguchi et al., 2016). Rupture data for the smooth specimens indicate shorter lives than for the notched specimens. This tendency is well known (Viswanathan, 1989, Webster et al., 2004) as "notch strengthening", and an example of modified 9Cr-1Mo steel is reported by Takahashi(2009). When compared with the averaged rupture curve for the welded joints, the lives for the smooth specimens are shorter. On the other hand, the data for the notched specimens correspond well with the averaged curve of the welded joints.

After these specimens ruptured at one of the double notches, the remaining notch was sectioned to examine the cavity density distribution. The cavity density was measured for an area of $0.36 \mathrm{~mm}^{2}$ on both the normal and parallel sections with respect to the axial direction. Figure 5 shows examples of the cavities observed at the center and near the notch root of the parallel section. Figure 6 shows the cavity density distribution along the minimum notch section on both parallel ("Axial" in Fig.6) and normal ("Circumferential" in Fig.6) section with respect to the axial direction. The creep cavity density of the sharp-notched specimen (R1) is high near the notch root, while that of the blunt notch (R3) is high at the center of the specimen. Based on the observation on the parallel section with regard to the axial direction, a similar tendency in the cavity density distribution at the blunt and sharp notches has been reported (Yoshida et al., 
2011, Kobayashi et al., 2013). With regard to the observation on the normal section, there are no reports at present. From the results shown in Fig.6, the cavity density distribution is almost the same in both the normal and parallel sections with respect to the axial direction; these results support the assumption made by the authors of the current report in the grain-boundary-resistance modeling of creep cavities (Fukahori et al., 2013, 2017). In the further discussion in this paper, the cavity density distribution on the parallel section with respect to the axial direction is used for comparing with simulation results.

Table 2 Test conditions and results.

\begin{tabular}{|c|c|c|c|c|c|c|c|}
\hline $\begin{array}{c}\text { Specimen } \\
\text { No. }\end{array}$ & Material & $\begin{array}{l}\text { Temp. } \\
\left({ }^{\circ} \mathrm{C}\right)\end{array}$ & $\begin{array}{c}\text { Nominal } \\
\text { Stress } \\
(\mathrm{MPa})\end{array}$ & $\begin{array}{l}\text { Rupture } \\
\text { Time } \\
\text { (h) }\end{array}$ & $\begin{array}{c}\text { Elongation } \\
(\%)\end{array}$ & $\begin{array}{c}\text { Reduction } \\
\text { of Area } \\
(\%) \\
\end{array}$ & $\begin{array}{c}\text { Minimum } \\
\text { Creep Rate } \\
(\% / \mathrm{h})\end{array}$ \\
\hline Smooth 1 & \multirow{4}{*}{$\begin{array}{c}\text { Simulated-HAZ } \\
\text { of } \\
\text { mod.9Cr-1Mo } \\
\text { steel }\end{array}$} & \multirow{4}{*}{650} & 80 & 74 & 52.8 & 93.1 & $1.21 \mathrm{E}-01$ \\
\hline Smooth 2 & & & 60 & 448 & 57.0 & 90.6 & $1.64 \mathrm{E}-02$ \\
\hline Notch R1 & & & 80 & 1,514 & 3.9 & 32.5 & - \\
\hline Notch R3 & & & 60 & 1,729 & 6.2 & 60.0 & - \\
\hline
\end{tabular}

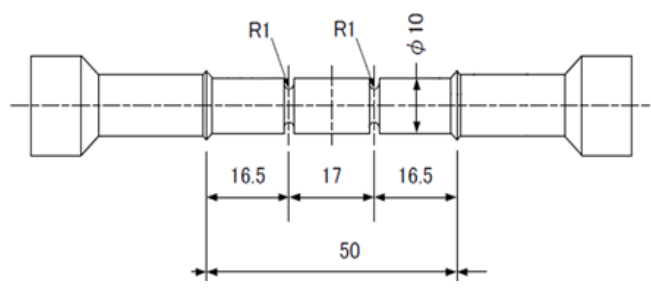

(a) R1 specimen

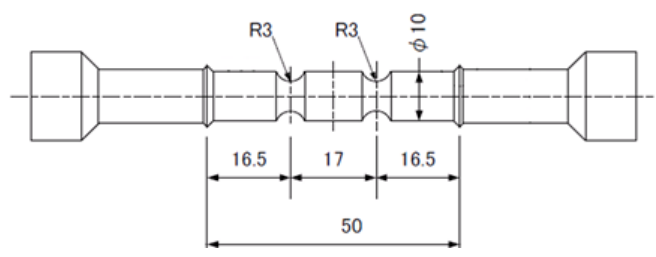

(b) R3 specimen

Fig.3 Configuration of circumferentially notched specimens

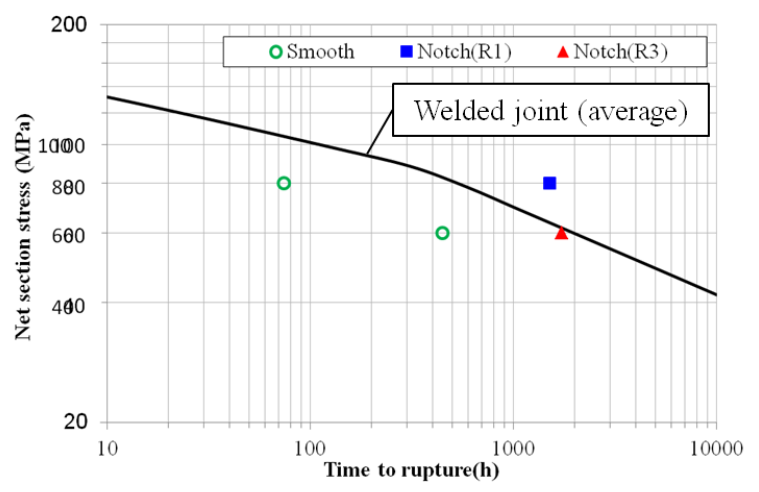

Fig.4 Stress versus rupture time 


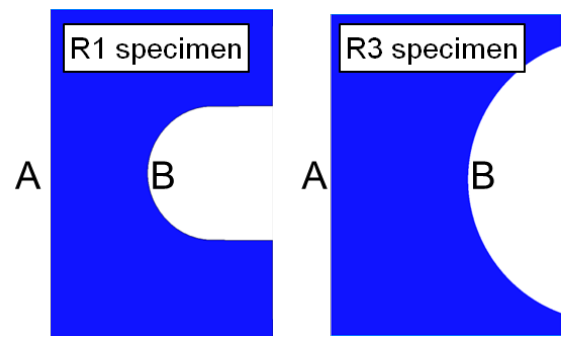

(a)Schematic illustration of observation area

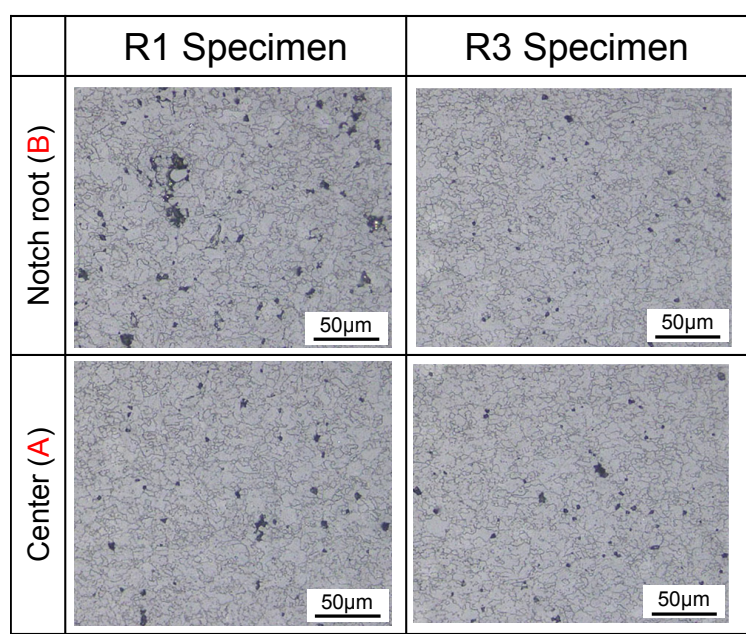

(b) Observed cavities

Fig.5 Observed cavities at several locations

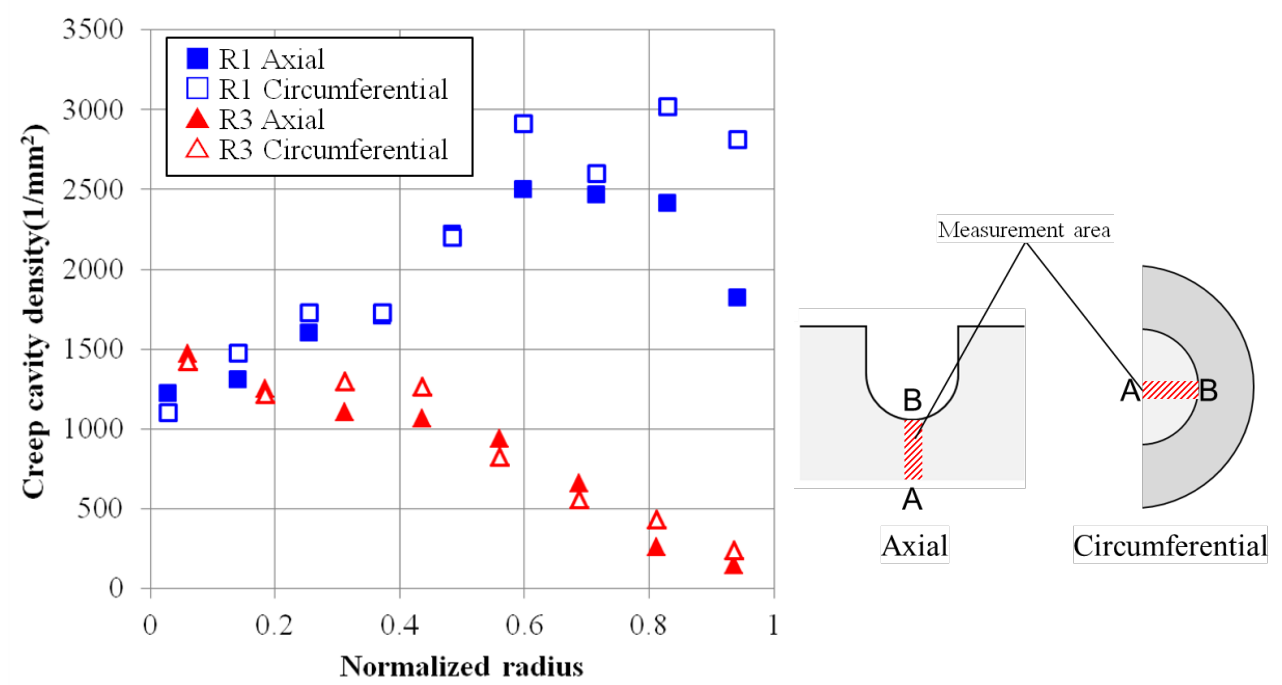

Fig.6 Cavity density distribution at the minimum section

\section{CDM constitutive law}

\subsection{Basic equations}

Perrin and Hayhurst (1999) proposed multi-axial creep damage constitutive equations by introducing multi-state variables as follows:

$\dot{\varepsilon}_{i j}^{c}=\frac{3}{2} A \sinh \left[\frac{B \sigma_{e q}(1-H)}{(1-G)(1-D)}\right] \frac{\sigma_{i j}^{D}}{\sigma_{e q}}$,

where $A, B, \sigma_{i j}^{D}, \sigma_{e q}, \dot{\varepsilon}_{i j}^{c}, H, G$ and $D$ are respectively two material constants, deviatoric stress, the von Mises equivalent stress, the creep strain rate and three state variables representing strain hardening during primary creep, softening due to precipitate coarsening, and damage due to nucleation and coalescence of the creep cavities.

Regarding the FGHAZ of modified 9Cr-1Mo steel, given that MX carbonitride precipitates from the initial state, the effect of strain hardening during primary creep is therefore considered to be small. Hence, $\mathrm{H}$ can be eliminated from Eq. (1), which is modified as follows:

$\dot{\varepsilon}_{i j}^{c}=\frac{3}{2} A \sinh \left[\frac{B \sigma_{e q}}{(1-G)(1-D)}\right] \frac{\sigma_{i j}^{D}}{\sigma_{e q}}$

Furthermore, the effect of strain softening is taken into account through the following evolution law (Toi et al., 2010): 
$\dot{G}=\alpha\left(\frac{\sigma_{e q}}{\sigma_{y}}\right)^{\kappa} \dot{\varepsilon}_{e q}^{c}(1-G)^{2}+\frac{K c}{3}(1-G)^{4}$,

where $\sigma_{y}$ is the yield stress, and $\alpha, \kappa$ and $K c$ are materal constants. Based on the creep curves of the smooth round bar specimens, material parameters with respect to softening were determined as shown in Table3. Meanwhile, Fig.7 presents a comparison between the experimental and simulated creep curves of the smooth specimens, showing the determination of material parameters to be acceptable.

Table 3 Material parameters in the analysis

\begin{tabular}{|l|l|l|l|l|l|l|}
\hline $\mathrm{A}(1 / \mathrm{h})$ & $\mathrm{B}(-)$ & $\alpha(\mathrm{h})$ & $\kappa(-)$ & $\mathrm{K}_{\mathrm{c}}(-)$ & $\mathbf{a}\left(1 / \mathrm{mm}^{2} / \mathrm{h}\right)$ & $\sigma_{\mathbf{y}}(\mathrm{MPa})$ \\
\hline $5.0 \times 10^{-7}$ & 0.1 & 20.0 & 3.0 & $1.0 \times 10^{-5}$ & 0.0375 & 200.0 \\
\hline
\end{tabular}

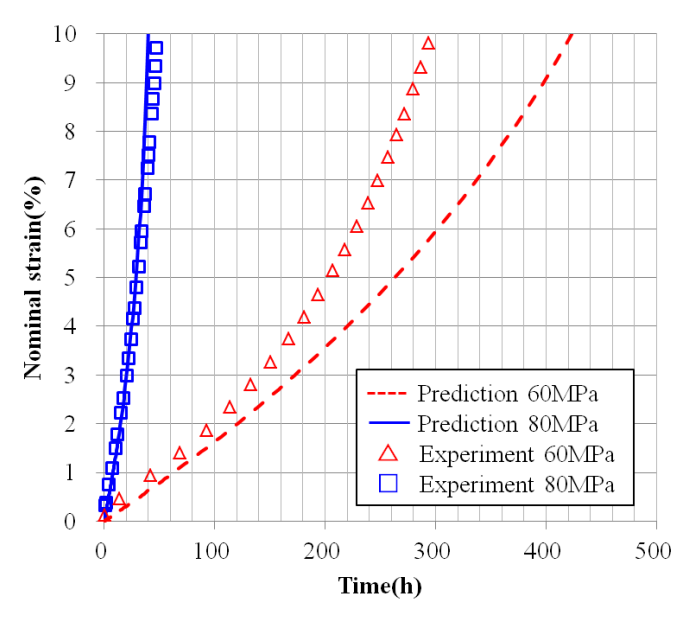

Fig.7 Creep curves of smooth round bar specimens

\section{Cavity nucleation model}

Gonzalez and Cocks (2014) proposed a cavity nucleation model applicable to the FGHAZ of P91under a multiaxial state of stress. The base line is the continuous cavity nucleation model of Dyson (1983) on a grain-boundary facet as shown below:

$\dot{N}=b\left(\frac{\sigma_{n}}{\sigma_{e}}\right)^{2} \dot{\varepsilon}_{e}^{c}$

where $b, \dot{N}, \sigma_{e}, \sigma_{n}$ and $\dot{\varepsilon}_{e}^{c}$ are respectively a constant, the rate of increase of cavity density, equivalent stress, stress normal to the grain-boundary facet of interest and the equivalent creep strain rate. Here we are interested in the rate of formation of cavities whose size is of the order of the FGHAZ grain size. As discussed in the Introduction, Matsuyama et al. (2013) demonstrate that these cavities form through the nucleation, growth and coalescence of much smaller cavities around the periphery of a grain. Gonzalez and Cocks (2014) assumed that the rate of formation of the grain-sized cavities is determined by the average rate of nucleation of small cavities around the grain perimeter. They considered the axisymmetric state of stress shown in Fig. 8 with radial and axial stress components, $\sigma_{r}$ and $\sigma_{z}$, which was expressed as a superposition of an isotropic state of stress $\sigma_{r}$, together with a uniaxial state of stress $\left(\sigma_{z}-\sigma_{r}\right)$. The stress state was then mapped onto a unit sphere in terms of the polar angle $\phi$ and azimuthal angle $\psi$. An infinitesimal area of the unit sphere is given by " $d \psi d \phi \sin \phi$ " and the stress normal to this element is " $\sigma_{r}+\left(\sigma_{z}-\sigma_{r}\right) \cos ^{2} \phi$ ". The rate of formation of the grain-sized cavities is then obtained by integrating the nucleation rate given by Eq. (4) over the area of the unit sphere and dividing by the area of the sphere, $4 \pi$, giving:

$\dot{N}=2 \int_{\psi=0}^{2 \pi} \int_{\phi=0}^{\frac{\pi}{2}} b\left(\frac{\sigma_{r}+\left(\sigma_{z}-\sigma_{r}\right) \cos ^{2} \phi}{\sigma_{e}}\right)^{2} \dot{\varepsilon}_{e}^{c} \frac{d \psi d \phi \sin \phi}{4 \pi}=b \frac{\dot{\varepsilon}_{e}^{c}}{\sigma_{e}^{2}}\left(\frac{4}{45} \sigma_{e}^{2}+\sigma_{m}^{2}\right)$ 
When using the tri-axiality factor $\mathrm{X}$ as below:

$X=\frac{3 \sigma_{m}}{2 \sigma_{e}}$,

and taking the formation rate under uniaxial loading (where $\dot{N}=a \dot{\varepsilon}_{e}$ ) as the reference state, Eq.(5) can then be written as follows:

$\dot{N}=a \dot{\varepsilon}_{e}^{c}\left(\frac{4}{9}+\frac{20}{9} X^{2}\right)$,

where $\sigma_{m}$ is the hydrostatic stress and $a=b / 5$. Eq.(7) represents the predicted rate of increase of cavity density for cavities of the order of the grain size in the FGHAZ of P91.

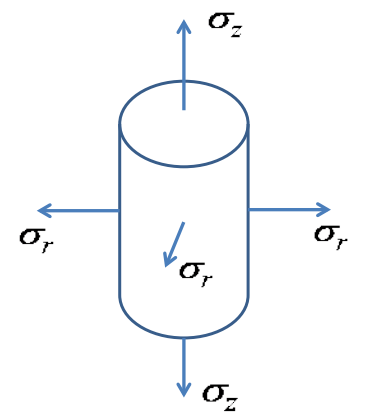

(a) Axisymmetric stress state

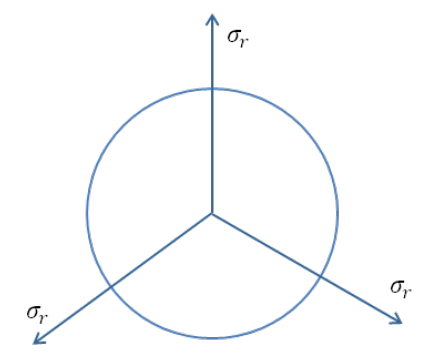

(b) Isotropic state of stress $\sigma_{r}$

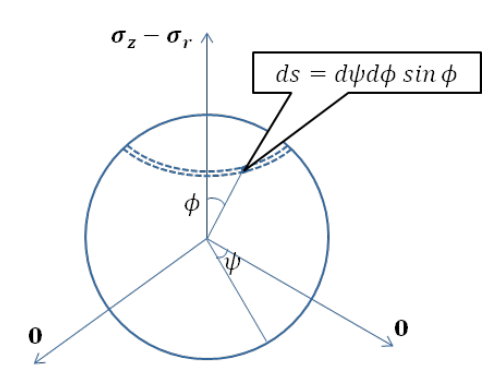

(c) Uniaxial state of stress of $\left(\sigma_{z}-\sigma_{r}\right)$

Fig.8 Stress state mapping of polycrystalline material with random facet direction

\section{Definition of creep damage}

Since the average size of creep cavities, i.e., the same size as the FGHAZ grain, is $5 \mu \mathrm{m} \times 5 \mu \mathrm{m}$, the creep damage variable $D$ becomes 1.0 when the number density of creep cavities $N$ reaches $40,000 / \mathrm{mm}^{2}$. The relationship between $D$ and $N$ is therefore defined as follows:

$D=\frac{N}{40000}$

According to the grain-boundary-resistance modeling simulation results by Fukahori et al. (2013, 2017), micro-cracks initiate by the coalescence of creep cavities when the creep cavity density reaches $4,000 / \mathrm{mm}^{2}$. Based on this result, the critical value of creep damage variable $D_{\text {cr }}$ is defined as below:

$D_{c r}=\frac{4000}{40000}=0.1$

Furthermore, to account for the reduction in stiffness due to damage (Lemaitre, 1985), the elastic modulus is defined as:

$E=E_{0}\left(1-\frac{D}{D_{c r}}\right)$

where $E_{0}$ is Young's modulus in the undamaged state.

\section{FEM analysis}

\subsection{Method}

Analysis of the notched bar was carried out using the damage mechanics model (CDM) and the cavity nucleation model described above. User subroutines for both the CDM constitutive law and the cavity nucleation model were implemented in the FEA solver ABAQUS. Numerical analyses were carried out so as to predict the damage and the creep rupture life of the specimens. Axisymmetric models with CAX4-type elements were constructed as shown in Fig.9. The element at the notch root had a maximum dimension of $30 \mu \mathrm{m}$. Young's modulus in the undamaged state is $160 \mathrm{GPa}$, and Poisson's ratio is 0.3 . The constant " $a$ " in the cavity nucleation model was calibrated with a peak value corresponding to the cavity density in the $\mathrm{R} 1$ specimen. The constants $\left(\mathrm{A}, \mathrm{B}, \alpha, \kappa, \mathrm{K}_{\mathrm{c}}\right)$ in the softening model were calibrated using the creep curve of the smooth specimen as displayed in Fig. 3 by assuming $\mathrm{D}=0$. 


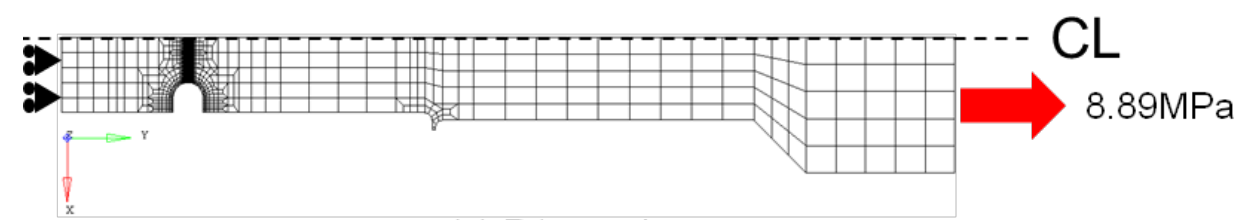

(a) R1 specimen

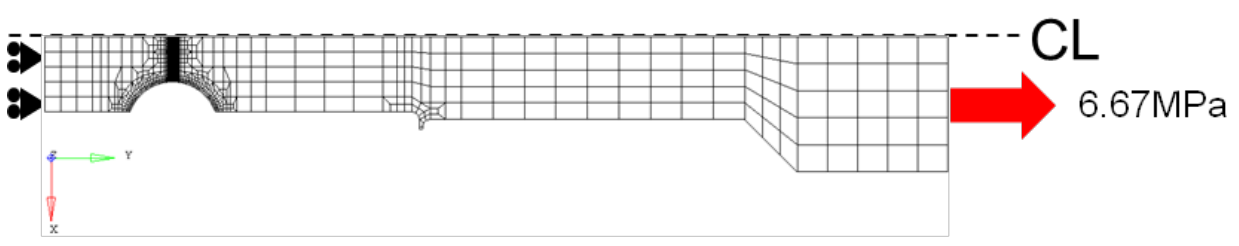

(b) R3 specimen

Fig.9 FEM model of notched specimen

\subsection{Results and discussion}

Figure 10 depicts the distribution of the tri-axiality factor in the $\mathrm{R} 1$ and $\mathrm{R} 3$ specimens at the life ratio $\mathrm{t} / \mathrm{tr}=0.5$, as an example, where $\operatorname{tr}$ is the rupture life. The tri-axiality factor is often used as the main factor influencing the damage distribution, but the cavity density profile for the R1 specimen does not correspond to the profile of the tri-axiality factor. Figure 11_shows the distribution of the equivalent creep strain rate at the same life ratio. For the R1 specimen a high peak is found at the notch root; and a flatter distribution is seen for the R3 specimen. Figure 12 shows the distribution of the creep cavity density across the notch root after $80 \%$ of the experimental rupture life. The reason for selecting $80 \%$ of creep life is because the cut section of the unruptured notch does not show micro-cracks even after the other notch has ruptured; the time when micro-cracks appear as a coalescence of creep cavities is the final stage of life at around $80 \%$ of creep rupture time (Fukahori et al., 2013, 2017). The simulation results using the nucleation model of Eqn (7) reproduce the trends exhibited by the experimental results in Fig.6 (experimental data on the parallel section with respect to the axial direction: notation "axial" in the figure). That is, the creep cavity density is highest near the notch root for the R1 specimen (sharp notch), and the creep cavity density peaks at the center for the R3 specimen (blunt notch). The calibration of the constant "a" in Eq.(7) is performed to match the peak of the cavity density of R1. Both the formulation of Eq.(7) and the calibration of the constant "a" are found to reproduce the experimental distributions of cavity densities in Fig. 12.

When considering Eq.(7), the cavity density is influenced by two factors: the equivalent creep strain rate and $\left(\frac{4}{9}+\frac{20}{9} X^{2}\right)$, which is a function of the tri-axiality factor X. Figure 13(b) and (c) respectively describe the influence of these two factors, and their product in Fig.13(d) is found to express the profile of the observed distribution of cavity density for both the R1 and R3 specimens. The equivalent creep strain rate together with the tri-axiality factor should be considered for expressing the cavity density profile in the notched specimens.

The macroscopic creep curves corresponding to the notched round bar from the experiments and the simulations are shown in Fig. 14. The vertical axis of the figure represents the nominal strain from a gauge length of $50 \mathrm{~mm}$. The rupture life from the simulation was determined as a time when the creep strain rate in an FEM element became very high and the simulation was stopped. The predicted lives for the R1 and R3 specimens from the simulations are respectively 1,230h and 2,994h. When compared with the experimental results for the R1 and R3 specimens, respectively of $1,514 \mathrm{~h}$ and $1,729 \mathrm{~h}$, the simulation results could predict the rupture time to within a factor of two. With respect to the nominal strain, the predicted results almost agree well with experimental results as can be seen in the figure.

When applying CDM to creep damage analysis, there are two types of deterioration mechanisms in the creep properties: one is softening due to precipitation coarsening, and the other is cavity-induced damage. In order to consider the influence of the damage mechanism, the simulation results of the following three cases are compared with each other. 
Case A: $\mathrm{D}_{\mathrm{cr}}=0.1$ \& Young' modulus of Eq.(10) ---Original

Case B: $\mathrm{D}_{\mathrm{cr}}=0.1 \&$ Young' modulus kept constant at $\mathrm{E}_{0}$---Influence of damage is neglected.

Case C: $\mathrm{D}_{\mathrm{cr}}=0.05$ \& Young' modulus of Eq.(10) ---Initiation of micro crack is $\mathrm{D}_{\mathrm{cr}}=0.05$

Case A is the original condition adopted in this paper; Case B is to check the influence of the damage on Young's modulus; Case $\mathrm{C}$ is to consider the influence of the critical damage related to the initiation of micro cracks. Since the macroscopic creep curves of the notched bar specimen were almost the same as the original curves, the predicted rupture lives for the notched round bar specimens are summarized in Table 4. When considering the R1 specimen, for example, the predicted rupture life in Case A, B and C are respectively 1,230h, 1,359h and 1,034h. Rupture life in Case $\mathrm{B}$ increased 10\% from Case A, and that in Case C decreased by 16\% from Case A. The influence of the cavity-induced damage was found to be small, since the critical value of the damage is small as shown in Eq.(9). As discussed in the literature (Fukahori et al., 2013, 2017), P91 FGHAZ grain boundary damage is highly localized on the final failure surface, and acceleration of the creep strain rate due to the increase of average damage is small. Although the influence of damage on Young's modulus in Eq.(10) is often considered in the damage mechanics approach, this influence is found to be minor. This is also due to the small value of the critical damage.

When considering an application of the present analysis to Type IV creep failure of welded joints, an additional consideration is necessary. In the FGHAZ with a width of $2 \sim 3 \mathrm{~mm}$, creep deformation properties are not uniform as expected from the hardness distribution in the FGHAZ; creep strain and cavities are considered to be localized around the boundary between the FGHAZ and the base metal. This tendency differs from the simulated FGHAZ notched bar specimen considered in this paper which has uniform creep properties. Further study of creep damage in welded joints with longitudinal and circumferential welds (Himeno et al., 2016) is required.

Table 4 Experimental and predicted life of notched specimens

\begin{tabular}{|l|l|l|l|l|}
\hline \multirow{2}{*}{ Specimen } & \multirow{2}{*}{ Experimental } & \multicolumn{3}{|c|}{ Prediction } \\
\cline { 3 - 5 } & & Case A & Case B & Case C \\
\cline { 3 - 5 } & & Dcr $=0.1$ & Dcr $=0.1$ & Dcr $=0.05$ \\
\cline { 3 - 5 } & & $\boldsymbol{E}=\boldsymbol{E}_{\mathbf{0}}\left(\mathbf{1}-\frac{\boldsymbol{D}}{\boldsymbol{D}_{\boldsymbol{c}}}\right)$ & $\boldsymbol{E}=\boldsymbol{E}_{\mathbf{0}}$ & $\boldsymbol{E}=\boldsymbol{E}_{\mathbf{0}}\left(\mathbf{1}-\frac{\boldsymbol{D}}{\boldsymbol{D}_{\boldsymbol{c}}}\right)$ \\
\hline R1 & $1,514 \mathrm{~h}$ & $1,230 \mathrm{~h}$ & $1,359 \mathrm{~h}$ & $1,034 \mathrm{~h}$ \\
\hline R3 & $1,729 \mathrm{~h}$ & $2,994 \mathrm{~h}$ & $3,061 \mathrm{~h}$ & $2,669 \mathrm{~h}$ \\
\hline
\end{tabular}

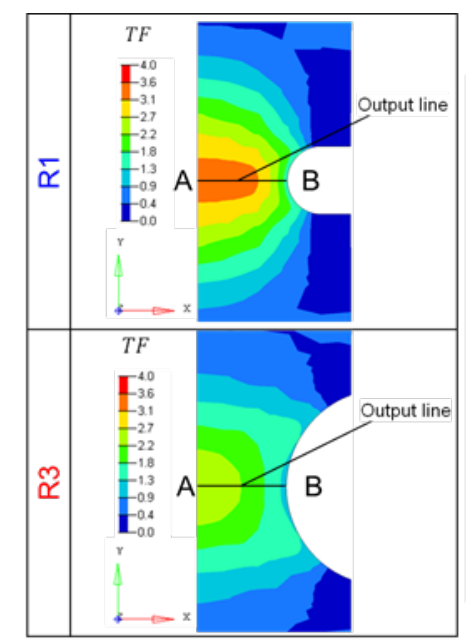

(a)Distribution of tri-axiality factor near the notch

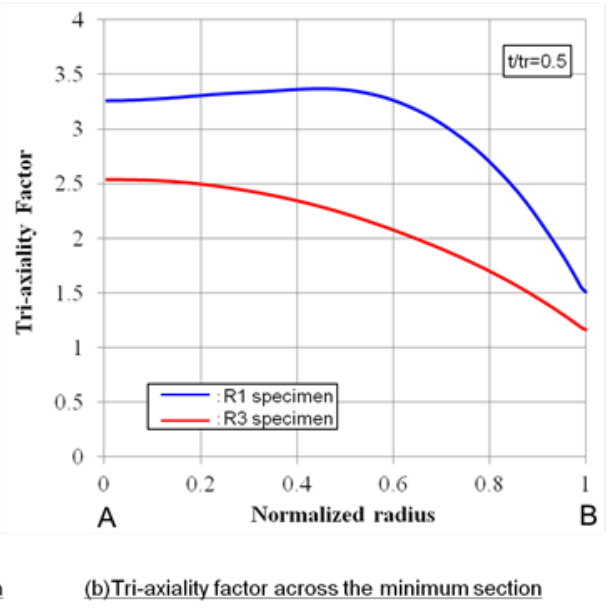

(b) Tri-axiality factor across the minimum section

Fig.10 Distribution of tri-axiality factor 

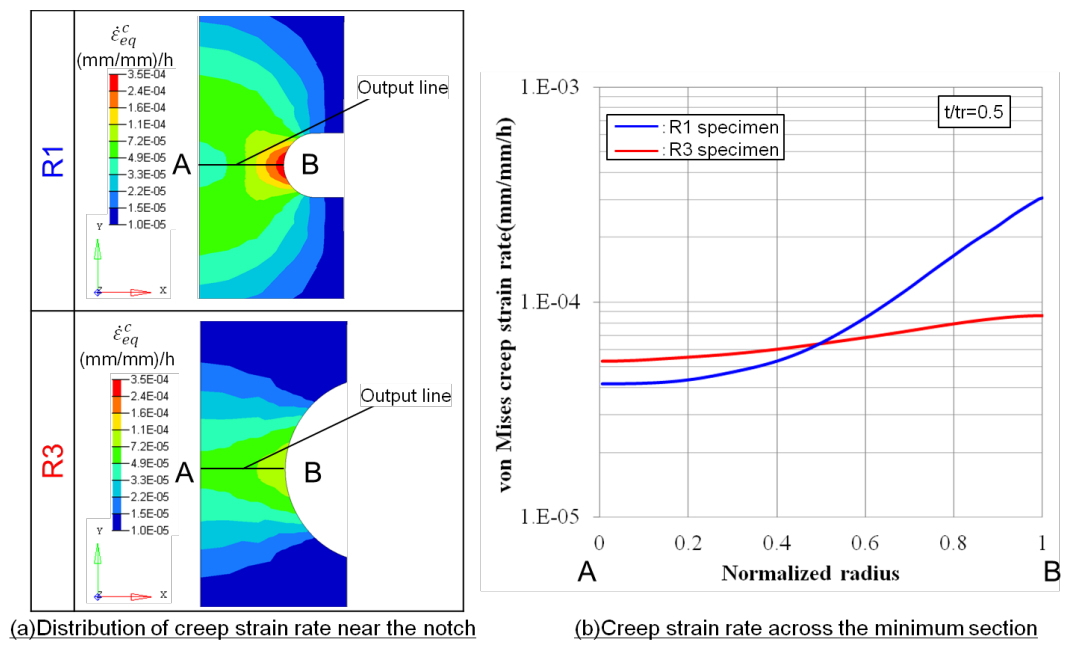

Fig.11 Distribution of equivalent creep strain rate

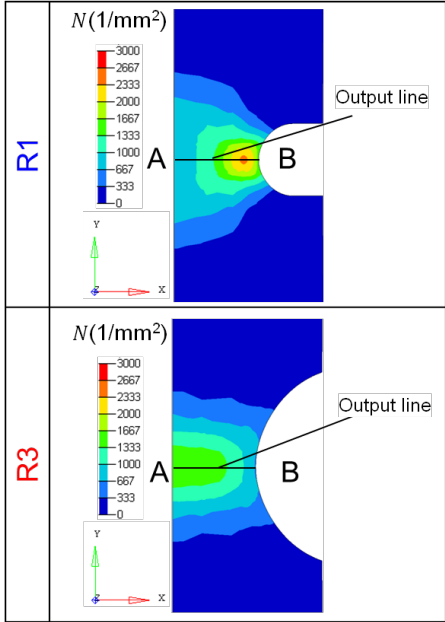

(a)Distribution of creep cavity density near the notch

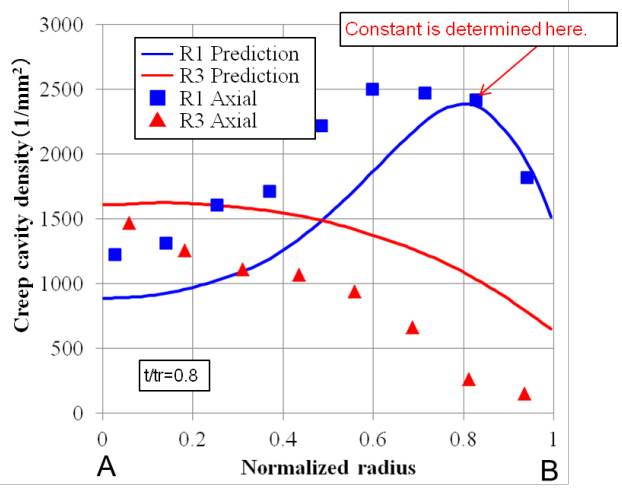

(b) Creep cavity density across the minimum section

Fig.12 Creep cavity density distribution from damage analysis 


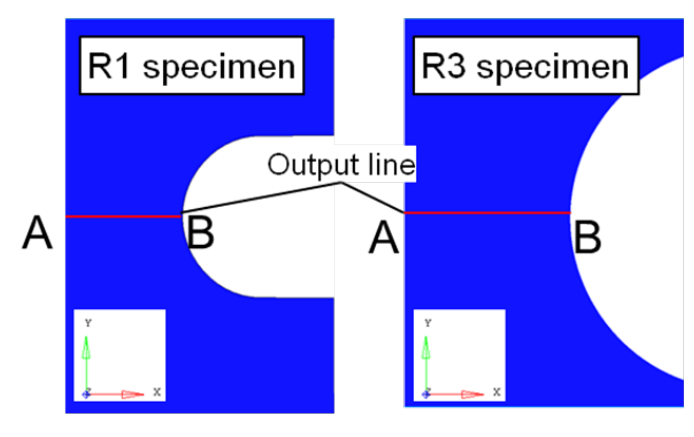

$\underline{\text { (a)Schematic illustration of output line }}$

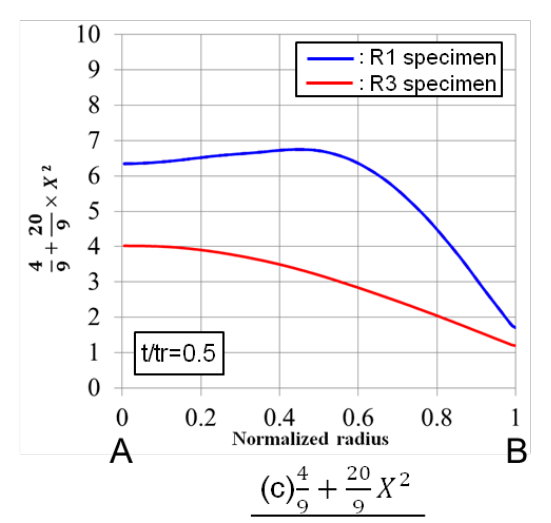

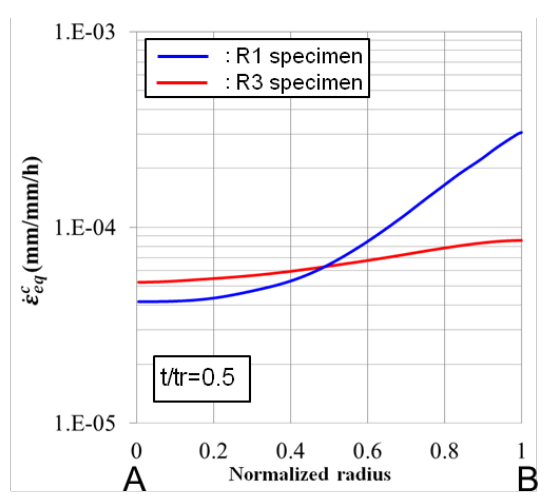

(b) $\varepsilon_{e}^{c}$

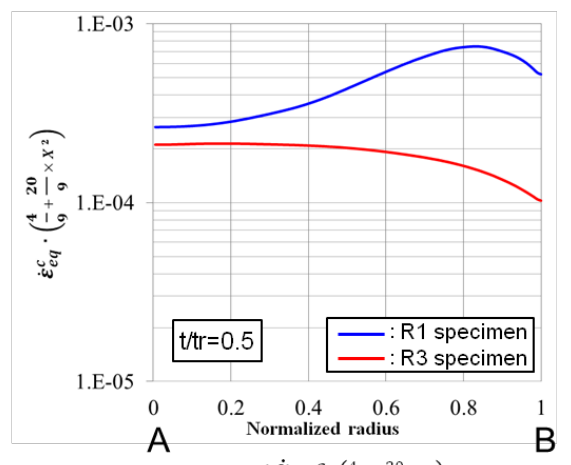

$\underline{(\mathrm{d}) \varepsilon_{e}^{c}\left(\frac{4}{9}+\frac{20}{9} X^{2}\right)}$

Fig.13 Factors influencing cavity density

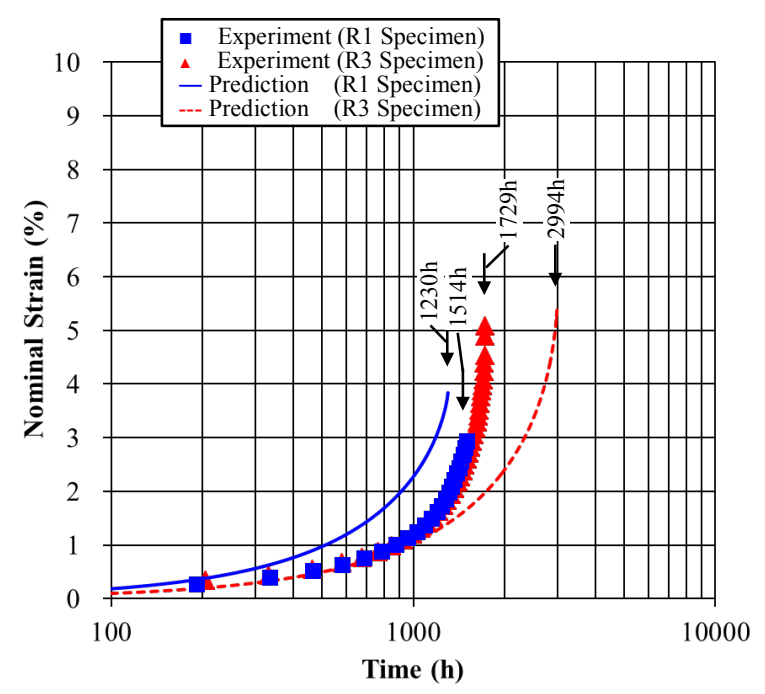

Fig. 14 Comparison of experimental and predicted nominal strain curves for notched specimens

\section{Conclusion.}

Comparing the simulated and experimental distributions of creep cavities in simulated FGHAZ notched bar specimens of P91, the applicability of the analysis method which combines CDM and creep cavity nucleation models has been demonstrated. The results thus obtained can be summarized as follows:

(1) The analysis in this paper is capable of expressing the distribution of creep cavity density for both a sharp notch with a peak near the notch root and a blunt notch with a peak at the specimen center.

(2) The final failure time of the circumferentially notched bar specimens was also predictable to within a factor of two. 


\section{References.}

Abe, F. and Tabuchi, M., Microstructure and creep strength of welds in advanced ferritic power plants steels, Science and Technology of Welding and Joining, Vol. 9 (2004), Issue 1,pp.22-30.

Dyson, B.F., Continuous cavity nucleation and creep fracture, Scripta Metallurgica, Vol. 17 (1983), pp. 31-37.

Fukahori, T., Tokiyoshi, T., Igari, T., Chuman, Y., Komai, N., Fujita, M. and Kawashima, F., Type IV damage evaluation for mod. $9 \mathrm{Cr}-1 \mathrm{Mo}$ steel welds based on microscopic creep damage simulation, Trans. JSME, Ser.A, Vol.78, No.789 (2012), pp.623-627 (in Japanese).

Fukahori, T., Tokiyoshi, T., Igari, T., Chuman, Fujita, M. and Kawashima, F., Microscopic simulation and life prediction of high $\mathrm{Cr}$ steel welds subject to Type IV creep damage, J. Society of Materials Science, Japan, Vol.62, No.2 (2013), pp.82-87 (in Japanese).

Fukahori, T., Tokiyoshi, T., Igari, T., Chuman, Y. and Komai, N., Prediction of Type-IV creep failure of a seam-welded mod. 9Cr-1Mo elbow based on microscopic damage simulation, Materials at High Temperatures, Vol.34, Issue 3 (2017), pp.194-207.

Gonzalez, D., Cocks, A.C.F., Fukahori, T., Igari, T. and Chuman, Y., Creep failure of a P91 simulated heat affected zone material under multiaxial state of stress, Proc. 3rd Intern. ECCC Conf. on Creep \& Fracture, (2014).

Himeno, T., Chuman, Y., Tokiyoshi, T., Fukahori, T. and Igari, T., Creep rupture behavior of circumferentially welded mod.9Cr-1Mo steel pipe subject to internal pressure and axial load, Materials at high Temperatures, Vol.33, Issue 6 (2016), pp.636-643.

Hyde, T.H., Sun, W. and Williams, J.A., Creep analysis of pressurized circumferential pipe weldments - A review, J Strain Analysis, Vol.38, No.1 (2003), pp.1-29.

Igari, T., Fukahori, T. Kawashima, F., Tokiyoshi, T. Chuman, Y., Komai, N. and Fujita, M., Micro-macro creep damage simulation for welded joints, Materials at High Temperatures, Vol.28, No.3 (2011), pp.181-187.

Kawashima, F., Igari, T., Tokiyoshi, T., Shiibashi, A., Tada, N., Micro-macro combined simulation of the damage progress in low-alloy steel welds subjected to Type IV creep failure, JSME International Journal, Vol.47, No.3 (2004), pp.410-418.

Kobayashi, K., Yoshida, K., Yoshida, K. and Yatomi, M., Nucleation and development of creep voids of P91 steel under multi-axial stress, Proceeding of HIDA-6, Nagasaki, Japan, 2-4 December (2013).

Komai, N., Tokiyoshi, T., Igari, T., Ohyama, H., Masuyama,F. and Kimura, K., Experimental observation of creep damage evolution in seam-welded elbows of mod. 9Cr-1Mo steel, Materials at High Temperatures, Vol.33, Issue 6 (2016),pp.617-625.

Lemaitre J., A continuum damage mechanics model for ductile fracture, Trans ASME J Eng Mater Technol., Vol.107(1985), pp.83-89.

Masuyama, F., Creep degradation in welds of mod. 9Cr-1Mo steel, Int. J. Pressure Vessels and Piping, Vol.83, Issue 11-12 (2000), pp.819-825.

Masuyama, F. and Yamaguchi, T,. Creep damage initiation mechanism and life of martensitic structures, Proceedings of $51^{\text {st }}$ Symposium on High-Temperature Strength of Materials (2013), pp.110-114. (in Japanese).

Perrin, I.J. and Hayhurst, D.R., Continuum damage mechanics analyses of type IV creep failure in ferritic steel crossweld specimens, Int. J. Pressure Vessels and . Piping, Vol.76, Issue 9 (1999), pp.599-617.

Rice, J.R., Constraints on the diffusive cavitation of isolated grain boundary facets, Acta Metall., Vol.29, No.4 (1981), pp.675-681.

Segle, P., Andersson, P. and Samuelson, L.A., Numerical investigation of creep crack growth in cross-weld CT specimens. Part I: Influence of mismatch in creep deformation properties and notch tip location", Fatigue Fract. Engng. Mater. Struct., Vol.23 (2000), pp.521-531.

Takahashi, Y., Creep rupture behavior of modified 9Cr-1Mo steel under multiaxial stress and its modeling, J. Society of Materials Science, Japan, Vol.58, No.2 (2009), pp.115-121 (in Japanese).

Toi, Y., Takagaki, M., Hirose, S. and Takahashi, Y., Analysis of Type IV creep damage behavior of high Cr steel welds, Seisan Kenkyu, Vol.62, No.1 (2010), pp.99-102.

Viswanathan, R., Damage mechanisms and life assessment of high temperature components(1989), p282, ASM International.

Webster, G.A., Holdsworth, S.R., Loveday, M.S., Nikbin, K., Perrin, I.J., Purper, H., Skelton, R.P. and Spindler, M.W., A Code of Practice for conducting notched bar creep tests and for interpreting the data, Fatigue \& Fracture of 
Engineering Materials \& Structures, Vol.27,Issue 4 (2004), pp.319-342.

Yaguchi, M., Nakamura, K. and Nakahashi, S., Re-Evaluation of Long-Term Creep Strength of Welded Joint of ASME Grade 91 Type Steel, ASME PVP2016-63316 (2016).

Yamauchi, M., Tokiyoshi, T., Chuman, Y., Nishimura, N. and Iwamoto, T., Creep damage evaluation procedure of weldments in high-energy piping, EPRI/DOE-conference on advances in life assessment and optimization of fossil power plants. March 11-13 (2002).

Yao, HT., Wang, Z. and Tu, ST., A review of creep analysis and design under multi-axial stress states Nuclear Engineering and Design, Vol.237, Issue 18 (2007), pp.1969-1986.

Yatomi, M., Nikbin, K.M. and O’Dowd, N.P., Creep crack growth prediction using a damage based approach, Int. J. Press. Vessels and Piping Vol.80 (2003), pp.573-583.

Yoshida, K.\& Yatomi, M., Creep damage evaluation for HAZ of mod. 9Cr-1Mo steels under multi-axial stress conditions, Procedia Engineering, Vol.19(2011), pp.490-495. 